\title{
Revista Eixo
}

Instituto Federal de Educação, Ciência e Tecnologia de Brasília

\author{
REITOR CONSELHO EDITORIAL \\ Wilson Conciani MSc. Carlos Ferreira Wanderley \\ Dra. Sônia Cristina Hamid
}

PRÓ-REITOR DE PESQUISA E INOVAÇÃO

Marley Garcia Silva

PRÓ-REITOR DE ENSINO

Adilson Cesar de Araujo

PRÓ-REITOR DE EXTENSÃO

Giano Luis Copetti CAPA

PRÓ-REITORA DE DESENVOLVIMENTO INSTITUCIONAL

Luciana Miyoko Massukado

Álisson Eduardo Gonçalves Ferreira

COORDENADORA DE PUBLICAÇÕES

Katia Guimarães Sousa Palomo

\section{PRODUÇÃO EXECUTIVA}

Fernando Coelho Barboza

PROJETO GRÁFICO E DIAGRAMAÇÃO

Álisson Eduardo Gonçalves Ferreira

\section{PRÓ-REITORA DE ADMINISTRAÇÃO}

Simone Cardoso dos Santos Penteado

SECRETÁRIA EDITORIAL

Raline Romaiany Oliveira Cardoso

PARECERISTAS

Dra. Aldelice Borghi Ferreira (UNISO - SP)

Dra. Carolina Vieira Silva (UFC)

Dra. Cláudia Roberta Ferreira (Fundação Bradesco)

Dra. Edna Duarte de Souza (UEG)

Dra. Elinilze Guedes Teodoro (IFPA)

Dra. Fatima Ivone de Oliveira Ferreira (Colégio Pedro II - RJ)

Dra. Lídia Suzana Rocha de Macedo (UFRGS)

Dr. Lorenzo Teixeira Vitral (UFMG)

Dra. Maria do Rosário Cordeiro Rocha (IFB)

Dra. Maria Ilza Zirondi (UEL)

REVISORES DE LÍNGUA PORTUGUESA

Guilherme João Cenci

Sheyla Villar Fredenhagem

\section{REVISORES DE LÍNGUA INGLESA}

Eber Gustavo Gomes Silva

Guilherme João Cenci

Tiragem: 500 exemplares

Dra. Patrícia Vaz de Lessa (UNIFIL - PR)

Dr. Renato Cabral Rezende (UFSP)

Dra. Rita de Cássia Marques Lima de Castro (INSPER)

Dra. Rosana César de Arruda Fernandes (SEEDF)

Dra. Sandra Fagionato (PMSC)

Dra. Sonia Regina Meira (FAEX - MG)

Dr. Vicente Concilio (UESC)

EDITORA

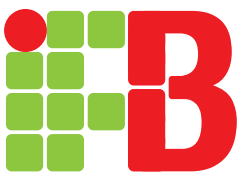

Reitoria - SGAN Quadra 610, módulos D, E, F e G

C.E.P.: $70830-450$ Brasília - DF

www.ifb.edu.br

Fone: +55 (61) 2103-2108

editora@ifb.edu.br 